\section{ESPECTADORES DE 3D: ¿EL FUTURO DEL CINE?}

\author{
Vicente Díaz Gandasegui \\ Departamento de C. C. Políticas y Sociología \\ Universidad Carlos III de Madrid \\ c/ Madrid 126, 28903 Getafe (Madrid) \\ vdgandas@polsoc.uc3m.es
}

\begin{abstract}
This paper analyses the reintroduction of $3 D$ to the big screen, this time, due to the digital technology and the polarization of the image, the focal depth has become more credible and the interface, in spite of still being present, is more comfortable and effective. The spectacular images attract the spectator to the cinema and captivate them with technological visual development. Simultaneously, 3D is a useful tool to solve contemporary cinema problems with piracy and competition with other media. However, the big question that $3 D$ has to solve is whether the new technology will join the large list of fiascos of the 70's and 80 's, trying to transform the way of seeing the image, or if it will be a step closer to virtual reality and a cinema of immersion and total interaction.
\end{abstract}

KEY WORDS: cinema; 3D; ReaID; spectators; interface; immersion.

La segunda década del tercer milenio quedará en la historia por la desaparición casi definitiva del soporte cinematográfico (...). El predominio del consumo y del espectáculo total, sostenido por los medios masivos en su transmisión digital, ha convertido al cine en un confuso híbrido tecnológico que ya no responde a las especificaciones significativas que lo definían (La Ferla, 2009, 195).

Desde el surgimiento de la modernidad ha existido una revolución artística y visual en cada uno de los períodos que la han sucedido: en el Renacimiento esta revolución hacía mención a la perspectiva; más adelante, en el siglo XX los espectadores se fascinaron con el movimiento producido por el cine y en el siglo XXI se comienza a atisbar el intento por producir una ruptura en la forma de observar, intentando hacer al espectador partícipe de las imágenes. En este sentido, el cine, que nace como una consecuencia de la unión de la máquina con el arte, se encuentra en este período en que nos encontramos en una nueva etapa

\section{3-D AUDIENCE: THE FUTURE OF THE FILM WORLD?}

RESUMEN: El presente artículo analiza la (re)introducción del 3D en nuestras pantallas de cine. Esta vez, gracias a la tecnología digital y a la polarización de la imagen, la profundidad de campo se hace mas creible y la interfaz, a pesar de seguir presente, ha ganado en comodidad y efectividad. La espectacularidad de las imágenes es el mayor reclamo que hoy presenta el 3D para atraer al espectador a las salas de cine y fascinarle con el desarrollo tecnológico. Al mismo tiempo, el 3D es una herramienta útil para solucionar los problemas surgidos en la industria cinematográfica a raíz de la evolución de la pirateria y la cada vez más compleja competición con otros medios. La gran duda que plantea el 3D es si se sumará a la larga lista de fracasos de los años 70 y 80 por intentar transformar la forma de ver la imagen o supondrá un paso adelante en la pretensión por acercarnos a la realidad virtual y un cine de inmersión e interacción total.

PALABRAS CLAVE: cine; 3D; ReaID; espectadores; interfaz; inmersión.

en su relación: el de la tecnología digital, fácilmente manipulable y que ofrece nuevas posibilidades a la imagen, acercándola al espectador (Diaz Gandasegui, 2008, 4). Es éste un cine, como nos dice Arlindo Machado, que nos aproxima al "mayor sueño de toda la aventura cinematográfica, el sueño de un cine permeable para el espectador en protagonista y sumergirlo íntegramente dentro de la historia" (Machado, 2009, 148).

La (re)introducción de una tecnología como el 3D ha significado un viraje significativo en la comercialización, exhibición y visionado de las películas que cuentan con este formato. La evolución actual de este fenómeno indica que probablemente lo que estamos viviendo no es más que un indicio del cine que está por llegar, el cual no ha sido explotado aún en su totalidad. De la misma forma, el concepto de espectador cinematográfico encierra una serie de actos simbólicos, valores y significados culturales que es pertinente analizar si sufrirán transformaciones relevantes 
con el (re)surgimiento de la tecnología 3D. En definitiva, las preguntas que se esconden bajo este cine de tanta exuberancia tecnológica es si el 3D es el futuro del cine, y por otro lado, si es técnicamente eficiente para sumergir al espectador en la película.

\section{EL 3D EN LA HISTORIA CINEMATOGRÁFICA}

El cine 3D ha constituido desde el comienzo del desarrollo del celuloide un proyecto, una ilusión y al mismo tiempo una doble paradoja: el intento por naturalizar la imagen a través de la artificialidad ofrecida por la tecnología y también la pretensión de convertir "la fábrica de sueños" en un producto que simultáneamente se asemeje y se distancie de la realidad que captamos a través de nuestros sentidos. Esto último implica el impulso contradictorio por recrear realidades lejanas de aquella en la que vivimos y al mismo tiempo "por capturar la vida y replicarla con movimiento, color, sonido y las tres dimensiones" (Zone, 2007, 4).

No hay que olvidar que vemos el mundo en tres dimensiones y al igual que el surgimiento del color en el cine doto a la imagen de una naturalidad que nuestro ojo cinematográfico tardó en aceptar, la aparición del 3D trata de emular el mismo camino (Katzenberg, 2009, 114). Así, cómo indica Valero Ruiz "la visión estereoscópica permite mostrar con mayor realismo diseños, formas y conceptos complejos de expresar en una imagen plana" (Valero Ruiz, 2000 , 1). El 3D complejiza la imagen con la intención de simplificarla, de hacerla visualmente más natural ofreciendo una diferenciación de planos inexistente en el cine clásico.

Sin embargo, en la ya dilatada historia del 3D, esta tecnología nunca pasó de una sucesión de fallidos intentos en los que ni la tecnología consiguió ser suficientemente creíble ni los productores, ejecutivos y cineastas de renombre quisieron embarcarse en una aventura en la que el 3D no pasaba de ser una distracción para el espectador'. Las películas en 3D se convirtieron a lo largo de la historia del celuloide en una persistente (y malograda) promesa de inmersión total en la película. De esta manera, una película en $3 D$, en sus múltiples formatos anunciados como la revolución definitiva de la tecnología visual, se convirtió en sinónimo de fracaso económico y se las estigmatizó por su falta de calidad cinematográfica.

La mayoría de estos proyectos de 3D se basaron en la captura de las imágenes mediante dos cámaras que grababan lo que verían cada uno de los ojos, posteriormente, tras una doble proyección y un visionado a través de gafas con filtros bicolores, la imagen original era percibida por el ojo al que pertenecía cada imagen. Así, al menos en teoría, el cerebro captaba las imágenes en tres dimensiones. Sin embargo, en la práctica la técnica era mucho menos eficiente. La impresión no pasaba de una leve y muchas veces deficiente impresión de profundidad de campo.

La aparición de la imagen del 3D viene ligada a la fotografía, pues tan temprano como en 1833, antes del surgimiento del cine, Sir Charles Wheatstone creo un ingenio consistente en un doble espejo para ver una imagen desde dos ángulos ligeramente distintos (Hayes, 1947, 1). En los años 50 y 80 se sucedieron dos fallidos intentos de resurgimiento de esta tecnología, esta vez aplicadas al cine, y ambas con la intención de ganar parte del terreno perdido con la televisión en la industria visual. En las dos ocasiones no pasaron de ser una promesa de nuevas sensaciones y su impulso inicial se fue extinguiendo a medida que el público se desencantaba con los resultados obtenidos. Su verdadero auge no llegaría hasta el siglo XXI, gracias a la aparición de RealD 3D. Esto supone, de alguna manera, el tercer resurgimiento del cine en 3D, Ray Zone establece este renacimiento en el 4 de noviembre de 2005, fecha en la que se estrena Chicken Little 3D (Dindal, 2005) (Zone, 2007, 4).

El medio cinematográfico, mientras tanto, ha mantenido una dualidad que se corresponde con aquellos que creen en la renovación y revolución permanente de las técnicas y la de aquellos otros, denominados puristas, que creen en el cine como un arte que debe mantenerse al margen de la influencia tecnológica para no coartar su capacidad de expresión y corromper sus principios. Este tradicional discurso se ha visto interrumpido de forma notable con la aparición del cine digital, del que RealD se ha beneficiado por ser el origen del nuevo 3D. Así, la imagen compuesta de un código binario se ha convertido en un requisito indispensable para su captación y exhibición. Una vez que la imagen digital se impuso a la analógica, los ceros y unos formaron las imágenes sustituyendo (imitando, se 
podría llegar a decir) a los fotoquímicos, y nuestra fe en el progreso tecnológico visual se ha hecho ilimitado. José María Paz Gago entiende que este cine digital y de artificios supone un elemento nuevo en el cine que supone un gran salto en su evolución:

la tridimensionalidad, los efectos de inmersión, la continuidad ilimitada del espacio, la interactividad y los efectos especiales generan, de cualquier modo, otro tipo de experiencia de recepción que va más allá de la experiencia ficcional y diegética, de naturaleza esencialmente visual (Paz Gago, 2004, 119).

El cine no ha muerto, como irónicamente anunciaba Peter Greenaway, a raíz de la introducción de artefactos cómo el mando a distancia y tecnologías digitales (Obando Arroyave, 2005, 50), únicamente ha evolucionado cómo tantas veces ha hecho durante su historia, siempre empujado por la búsqueda de satisfacer las necesidades del público y lograr un mayor éxito comercial. Quizá su nuevo formato digital suponga un gran salto en su evolución, lo que le sitúa en un status diferente, pero ésta no es la primera ni la última vez que ocurrirá en su historia. En este sentido, Greenaway advierte que "si el cine pretende sobrevivir, entiendo que debería hacer un pacto y relacionarse con los conceptos de interactividad y considerarse una parte de la aventura cultural multimedia" (citado en La Ferla, 2009, 26).

\section{ReaLD 3D}

Es a partir de mediados de la primera década de este siglo cuando una nueva fórmula tecnológica, el ReaID 3D devolvió la vieja idea de una tercera dimensión a la gran pantalla. El 3D aparece hoy en día como consecuencia de la demanda constante (y de alguna manera contradictoria) del espectador de recibir productos cada vez más reales y que sean simultáneamente espectaculares. En este sentido, la pantalla cinematográfica se convierte en el medio ideal, pues ésta no hace distinción entre la verdad y los hechos manipulados (Vera, 2008, 41-42).

Lo cierto es que ReaID 3D ha hecho mucho más creíble la tecnología 3D para todos aquellos que éramos altamente escépticos sobre la posible (re)aplicación de esta vieja ilu- sión cinematográfica. EI 3D se presenta así hoy de manera distinta a su primera aparición en el cine, no tanto como una alternativa a la narrativa sino como un complemento que podrá ser usado por los mejores directores (Katzenberg, 2009, 113). Real D se define a si misma cómo una tecnología brillante, ultrarrealista y tan viva que parece que el espectador se ha adentrado en la película, con objetos que se lanzan a la sala. La publicidad de ReaID 3D nos avisa de que no sólo se ve la película, realmente se puede sentir, convirtiéndose así en una nueva dimensión en el entretenimiento (Cowan, 2007).

En lo que a mi experiencia con RealD 3D respecta, me faltaron pocos minutos, los que tardaron los créditos en hacer su aparición en Beowulf $3 D$ (Zemekis, 2007), para reconocer que lo que estaba presenciando poco tenía que ver con el atisbo de profundidad de campo de otras películas que había visto cuando era pequeño [Tiburón 3D (Alves, 1983], es la que primero viene a mi memoria) y que me habian dejado una sensación de decepción y desesperación una vez se encendian las luces y abandonaba la sala. Lo primero que me llamó la atención fueron las gafas: el plástico había sustituido al papel, las lentes de colores habían dejado paso a unos cristales tintados y mientras me acomodaba en la butaca no podía remediar que mi escepticismo aumentase con aquellas grandes gafas de sol en la mano. Pese que la comodidad no era total y la sensación de tener una interfaz en la cara seguía siendo constante y patente, las gafas funcionaban mucho mejor de lo que habia esperado y en un acto de curiosidad inconsciente no dejé de levantar las gafas para verificar que aquello era diferente.

En efecto, el RealD 3D sigue el mismo principio de las antiguas gafas bicolores, pero en este caso, gracias a la tecnología digital, es la polarización circular la que otorga a la imagen estereoscópica de una mayor y mejor profundidad de campo. Es de esta forma como un único proyector emite unas imágenes para el ojo derecho polarizando las imágenes circularmente siguiendo las agujas del reloj y a su vez lo hace para el ojo izquierdo en sentido contrario. Las gafas tienen polarización inversa en cada una de sus lentes para asegurarse que cada ojo únicamente observa las imágenes destinadas a sus respectivas retinas, esto es posible debido a que la luz polarizada no afecta a la imagen y es en general invisible para el ojo humano (Fernández Sánchez, 2000, 4). Gran parte del secreto del 
3D se encuentra en una triple emisión de cada una de las imágenes y una pantalla gris metalizada que ayuda a reducir tanto los reflejos como a mantener el brillo y contrastes adecuados. El resultado son 144 imágenes por segundo, es decir, cada ojo ve 72 imágenes por segundo, lo que garantiza la fluidez de la imagen y elimina el indeseado efecto "fantasma", que provoca que el ojo izquierdo capte las imágenes del ojo derecho. El resto de la magia se encuentra en nuestro cerebro, el efecto Phi, lo denominó Hugo Münsterberg (2004), que compone las imágenes de tal forma que las imágenes obtienen fondo y perspectiva.

Es de esta manera cómo el cine de las atracciones relatado por Tom Gunning (2004: 866) cobra un nuevo sentido: el espectador se fascina con la transformación de la imagen a través de la nueva ilusión proyectada en movimiento. Existen ciertamente analogías entre como confrontan los avances tecnológicos de la imagen los espectadores de RealD y los primeros espectadores del cine. Los espectadores ya no salen corriendo de sus butacas, como relataba el viejo mito de las primeras audiencias cinematográficas, que no llegaban a comprender como un tren parecía entrar en la sala dispuesto a arrollarlos; hoy en día tenemos que levantar ligeramente las gafas polarizadas cuando nos parece ver a una flecha acercarse, para comprender, de esta manera, que los objetos siguen allí, en la pantalla. La reacción de los espectadores es similarmente ingenua, pero lo que nos queda por saber es si los espectadores terminarán integrando esta tecnología a la forma de ver el cine, mediante una "educación de la retina", de la misma manera que comprendimos que los objetos que percibimos en el cine o la televisión son únicamente proyectados en la pantalla. La cuestión es saber cuanto tiempo durará la curiosidad de los espectadores por la imagen en 3D y si la desaparición de esta curiosidad y la familiaridad con sus efectos acarreará una perdida de interés por el impacto de esta tecnología o por el contrario supondrá una necesidad y requisito indispensable a la hora de ver cine.

El sistema ReaID 3D pretende obtener una mayor inmersión de los espectadores en la película y al mismo tiempo conjugar la eficacia técnica de la imagen con una buena calidad cinematográfica. Esto responde a que "nuestra sociedad ya no quiere sólo ver un espectáculo, sino adentrarse en él" (De Kerckhove, 2010, 3). Para ello y a partir de 2005 se han estrenado películas con un éxito relativo en las taquillas y que como ocurre en el caso de Up 3D (Docter y Peterson, 2009) consiguen aunar también el beneplácito de los críticos de cine. Up es una película de la factoría Pixar que, con un uso moderado del 3D, consigue que los espectadores no sólo se fascinasen con la imagen sino que también disfruten con la historia, consiguiendo que la tecnología y la diégesis de la película se complementen para sumergir al espectador en la película.

Un hecho que no debe pasar desapercibido es que la gran mayoria de las películas estrenadas desde la aparición de RealD 3D y las que han obtenido mejores resultados de critica y público han sido aquellas en las que las imágenes están generadas de forma artificial, bien en forma de animación o con una mezcla de imágenes creadas por ordenador e imágenes captadas con la lente de la cámara. La captación de la realidad es de alguna manera desestimada por la tecnología 3D de última generación, lo que añade un componente de confusión a la (i)rrealidad de este tipo de películas. Al mismo tiempo y unido a ello, el 3D se hace especialmente eficiente en géneros como el fantástico o la ciencia ficción, que nos enseñan un futuro y/o otros mundos que necesitan de la tecnología para ser creados.

Avatar (Cameron, 2009), un proyecto que comenzó quince años antes de su comercialización, dio una vuelta de tuerca más a la utilización del 3D con una historia de fantasía en una película eminentemente visual y espectacular. Avatar es una película que atrae al público por brindar un deleite estético, pero también ofrece el desplazamiento del mundo que conocemos a un universo de ficción que se abalanza sobre nosotros, o a la inversa. James Cameron, su director, justificó la utilización de ReaID 3D en Avatar aludiendo al futuro de la tecnología visual: "3D es cómo vamos a experimentar las películas, los videojuegos y los ordenadores en un futuro cercano. 3D no es algo que se vea, es una realidad en la que uno siente que puede adentrarse" (Butler, 2009, 21). Avatar nos introduce en un mundo distinto, creado a base de la última tecnología en efectos especiales, y para ello, para que el espectador se sumerja en este mundo desconocido, le lanza las imágenes hacia el. Avatar pretende la inmersión del espectador en la película utilizando la imagen y el $3 \mathrm{D}$ es en este caso una herramienta más en su propósito;

En lugar de permitirme ver el espectáculo desde fuera, me lleva dentro de la escena, o incluso hace que me vea envuelto por ella. Voy alli en el sentido literal de ir a un sitio, 
entro en el interior $y$, si no puedo ir, es el espectáculo el que viene a mi y me penetra (De Kerckhove, 2010, 2).

Para todos aquellos que hemos tenido la oportunidad de ver la película en sus dos versiones, en las clásicas dos dimensiones y en 3D, no cabe ninguna duda de que el $3 \mathrm{D}$ consigue aportar algo más que impacto visual ya que la inmersión en la película se produce de forma diferente al cine clásico. Si Avatar es vista en su versión en dos dimensiones, sobre todo si esto ocurre en una pantalla de televisión, la película no termina por presentar grandes novedades, únicamente un desarrollo y perfeccionamiento de las técnicas de recreación digital, un "cine-espectáculo que no ha hecho más que retomar algo de sus orígenes y ha conquistado ese cine de atracciones que el cine clásico rechazó" (Pereira Dominguez, Solé Blanch y Valero Iglesias, 2010, 3). Sin embargo, Avatar 3D presenta una novedad en cuanto a la forma en que la (i)realidad de la película, estética y narrativa, son percibidas por los espectadores, con una ficción que envuelve al espectador, lo que redunda en el espectáculo y entretenimiento.

Es ahora, con Avatar 3D, cuando "puede comenzar una nueva generación del cine. El 3D ya no es una moda, sino una necesidad cultural de la nueva sociedad del espectáculo, que se define también como sociedad de la participación" (De Kerckhove, 2010, 2). En este sentido, el discurso establecido en los años sesenta por Guy Debord sobre la sociedad del espectáculo no solamente sigue vigente, sino que ha sido renovado por el desarrollo tecnológico que produce un "puro masajeo retiniano" (La Ferla, 2009, 46) y la satisfacción por participar en los productos culturales que consumimos. Establecía Debord (2000, 51-61), que nuestra sociedad de medios de comunicación y consumista se organiza entorno a una producción y consumo de imágenes en las que la realidad es presentada cómo espectáculo y lo espectacular como creíble. Esta es la dualidad que nos ofrece Avatar mediante un simple trueque: un mundo futuro creíble y un mundo lejano espectacular.

Sin embargo, cabe aclarar que pese a la espectacularidad de películas como Avatar, el ReaID 3D, no ofrece de forma literal una imagen en tres dimensiones sino un efecto (ilusorio) de perspectiva, de diferenciación de planos, con objetos y personajes que parecen tener una distancia palpable entre ellos y acercarse al espectador. Las flechas se acercan amenazantemente al espectador, detrás de un personaje hay un árbol, pero ¿podemos ver ese árbol o esa flecha desde un ángulo distinto? El espectador, como ha hecho siempre, permanece inmóvil y son las imágenes las que le ofrecen una perspectiva diferente, puesto que la cámara sigue sin ser subjetiva. Al fin y al cabo, "la tridimensionalidad del espacio representado es algo que el espectador puede suponer, pero no experimentar. Las posiciones y movimientos del espectador no alteran la imagen y que está vista por otro" (Machado, 2009, 155).

La tecnología 3D puede ser utilizada con resultados efectivos tal y como ha quedado mencionado con los ejemplos de Beowulf, Avatar y Up! Pero la inmersión en la película sigue siendo compartida por un guión y una realización que permite al espectador olvidar el mundo que le rodea y utilizar sus experiencias y memorias para trasladarse a la (i)rrealidad que le propone la película, el efecto espejo le Ilamo Christian Metz, de los espectadores con los personajes que aparecen en la pantalla. Así, una buena tecnología 3D no pasará de un mero distraimiento si el espectador no disfruta de la película o si la concentración, por factores personales o externos, no es suficiente para olvidar el mundo en el que vive y sumergirse en el mundo diegético del film.

\section{ESPECTADORES DE 3D}

Quien se sienta en la sala contribuye a construir lo que aparece en la pantalla (Casetti, 1989, 22).

El aparato cinematográfico ha sido entendido desde Louis Althusser por el conjunto que componen la tecnología fílmica, el espectador y su psicología, esto es, la distancia simbólica y cognitiva entre la imagen y el espectador; su buen funcionamiento individual y agregado previene al espectador para no considerar la ausencia de realidad existente y aceptar la ilusión que se le muestra (Aaron, 2007, 9-14). Esta combinación, la interacción existente entre estos tres elementos, se ve alterada con el 3D y la digitalización, implicando un aparato cinematográfico (ligeramente) distinto, especialmente en lo referente a la distancia cognitiva entre el espectador y la imagen. El resultado, la falta de realidad, es menos obvio gracias al desarrollo tecnológico, que en etapas anteriores de la historia del cine: la imposibilidad de diferenciar la realidad e 
irrealidad en la pantalla hace que el espectador no distinga entre los elementos captados por la lente y los generados artificialmente $y$, por otro lado, la distancia entre la imagen y el espectador se reduce, lo cual es algo menos que metafórico, si tenemos en cuenta la cercanía que en muchos momentos muestran los objetos.

La relevancia adquirida por la imagen en el cine espectacular que promulga el 3D hace que la ilusión de realidad lo sea todo y por ello su falta de convencimiento anula, en gran parte, el efecto de inmersión en la película por parte del espectador. La diégesis de la película sigue estando presente y es un factor fundamental, pero lo que varía respecto al cine clásico es su relación e importancia respecto al espectáculo de la imagen, los espectadores no van al cine, fundamentalmente, por la historia que se les cuenta sino por el espectáculo que se les brinda, "para maravillarse ante su representación como para preguntarse cómo lo han hecho" como menciona Darley $(2002,183)$. A diferencia del cine clásico la presencia en el espectador del "cómo lo han hecho" no anula el hechizo del cine 3D y la ilusión de realidad. El espectáculo es ahora magia y la sorpresa ante lo que creíamos imposible supone parte del espectáculo y no una distracción.

El 3D RealD nos ofrece una película que se produce y consume como un espectáculo, "la propia tecnología es el mensaje", nos dice Darley $(2002,92)$ dándole una vuelta de tuerca a las palabras de McLuhan (el medio es el mensaje, pronunció este último en "Understanding Media: the Extensions of Man", en 1964). Los espectadores de 3D no van únicamente al cine a ver una película, acuden a disfrutar de la tecnología que permite asustarse y reaccionar a las imágenes de forma visceral; paradójicamente esto es diferente a cómo lo habían hecho hasta entonces con el cine clásico, pero semejante a como se disfrutaba de las ferias y de las atracciones populares.

\section{El eSPECTÁCULO DEL 3D}

No todas las películas pretenden ser espectaculares, aunque todas intentan entretener al espectador de una u otra forma. Por esta razón, no todas las películas se beneficiarían de la tecnología 3D por mucho que esta técnica se perfeccione en el futuro ¿Se beneficiaría Ciudadano Kane
(Welles, 1941) ó Casablanca (Curtis, 1942) del 3D? Seguramente distraería al espectador, con sus efectos visuales, de la estética y diegética cinematográfica que intentan transmitir estas películas, obteniendo un resultado poco ventajoso. El espectador, en definitiva, no obtendría una mejor experiencia por el hecho de visualizar estas películas con una mejor profundidad de campo, me atrevo a decir, que el resultado empeoraría la versión original.

Pero si ser espectacular es la intención fundamental de la pelicula, algo muy común en el cine comercial hoy en día, el 3D ayuda realmente a causar este efecto. Este tipo de películas supertaquilleras, tecnológicamente densas y repletas de efectos especiales, se convierten en "el emblema principal del reciente giro que se ha dado hacia la imagen y la forma" (Darley, 2002, 163). La imagen espectacular, rentable y de "rápido consumo" parece predominar hoy en día en las producciones, las taquillas de cine, los videojuegos y los canales de televisión, lo que es un indicio del próspero futuro que le espera a tecnologías como el $3 \mathrm{D}$ y posibles desarrollos técnicos de este.

\section{LA INTERFAZ}

Hoy en día el espectáculo del 3D sigue estando íntimamente ligado a la presencia de las gafas polarizadas, las cuales permiten al espectador disfrutar de la magia de la imagen. Este es el peaje que el espectador ha de pagar (lo cual no es metafórico, pues el uso de las gafas tiene un coste adicional) para poder recrearse con una mejor profundidad de campo. Las gafas estereoscópicas tienen además unos impactos directos e indirectos sobre el espectáculo: posibles dolores de cabeza (Peirón, 2010), pérdida de calidad de la imagen (en lo referente al brillo, color y contraste, pese a que la nueva tecnología lo haya paliado notablemente), la incomodidad que supone para aquellos que utilizan gafas de corrección para la vista y, sobre todo, una constante sensación de que la interfaz está siempre presente.

En un momento en el desarrollo tecnológico en el que tratamos de deshacernos de todo aquello que supone una conexión física, de los cables y los teclados, el uso de gafas estereoscópicas para ver 3D supone un avance no del todo satisfactorio de la imagen. Si bien la presencia y conocimiento de la interfaz no afecta de forma determinante 
al disfrute del espectáculo, si que disminuye el efecto de inmersión en la película y de alguna manera reduce al mismo tiempo las técnicas cinematográficas y convenciones fílmicas que hacen que nos sumerjamos en la película. El conocimiento de las condiciones del artificio nos recuerda el mundo físico que habitamos, pues los espectadores ganan consciencia sobre su estatus de espectadores de cine (Tim Marsh y Peter Wright, 2000, 3).

EI 3D aplicado a largometrajes produce un disfrute y fascinación del espectador sobre el desarrollo tecnológico de la imagen, pero paradójicamente, en lugar de inmersión puede llegar a provocar el efecto contrario al deseado: hacer muy patente y centrar al espectador en lo que debería ser una herramienta oculta e inapreciable entre el espectador y las imágenes que observa, como ocurre en Viaje al Centro de la Tierra (Brevig, 2008), una producción que nos recuerda a los fallidos intentos de los 80 por introducir el $3 \mathrm{D}$ en el cine: lo único que nos llama la atención (para bien o para mal) de la película es el 3D. En este sentido, cabe preguntarse si los espectadores se pueden terminar cansando de lo que ahora mismo supone una novedad ¿Es el nuevo concepto del 3D una moda pasajera o el principio de la una larga relación con el cine? Lo cierto es que el 3D en su actual formato tiene muchas posibilidades de convertirse en el primer eslabón de una serie de tecnologías visuales, aún incipientes, que transformarán la forma y el modo en que el espectador consuma las imágenes.

En este sentido, la realidad virtual, la cual no es hoy en día una alternativa al cine convencional y a la tecnología 3D, se divisa en el horizonte como el posible futuro del cine. Un cine personal, con imágenes que son creadas por otros, pero recreadas por el espectador y en el que el jugador/ espectador se sumerge totalmente en el mundo virtual. Sin duda, la interfaz, que debe ser capaz de trasmitir imágenes polisensoriales, es actualmente el mayor obstáculo que separa a la realidad virtual tanto del cine como del éxito comercial.

El futuro (muy lejano, quizá) podría ser la conexión de nuestro sistema nervioso a la tecnología, tal y como describe la película eXistenZ, en la que el juego converge en el jugador, dando como resultado la inmersión total en la ficción o virtualidad propuesta y la anulación del efecto adverso que supone la interfaz ${ }^{2}$. Se trataría de ocultar la artificialidad que reporta la virtualidad (Tim Marsh y
Peter Wright, 2000, 3) para que la experiencia nos resulte absolutamente natural.

\section{OTROS MEDIOS: TELEVISIÓN, VIDEOJUEGO Y REALIDAD VIRTUAL}

Los nuevos medios han modificado nuestro concepto de la imagen, porque transformaron al observador en un usuario activo (Manovic, 2001, 183).

Nada de lo que se produce tendría cabida, por muy espectacular que fuese, si no tuviese una aceptación social y por lo tanto una retribución financiera que hiciese la inversión positiva y viable. La industria cinematográfica se enfrenta, una vez más, a la necesidad de combatir los viejos y nuevos enemigos del medio cinematográfico: la oferta de otros medios, que se ha visto incrementada de forma notable recientemente, y, sobre todo, la piratería. Hoy en día el consumo de películas es mayor que en cualquier otro momento en la historia del cine, pero el consumo de estas en salas cinematográficas es menor que hace veinte años en América y Europa (García Canclini, 2007, 36). Esto es debido a que el cine se ve mayoritariamente en casa: en televisión, DVD o por Internet.

Para enfrentarse a esto, el espectáculo del cine en 3D era hasta hace poco exclusivo de la gran pantalla y pese al gasto extra que debía afrontar el espectador, la experiencia recompensaba a quien abonaba este suplemento pues la tecnología doméstica carecía de esta posibilidad. Hoy el $3 D$ se ha adentrado en nuestro hogar y no es necesario acudir a una sala de cine y pagar el precio extra por una entrada para disfrutar de un espectaculo en 3D: la empresa tecnológica Samsung ha hecho una fuerte apuesta ofertando la tecnología 3D en su última gama de televisores. Ya no es únicamente el desarrollo en la calidad y cantidad de la imagen, sino también la cualidad, pues se nos invita a ver desde el sillón de nuestro salón la televisión en 3D. Sin duda, ésta es una de las grandes revoluciones en la constante evolución de la tecnología digital y al mismo tiempo nos sitúa en el comienzo de un posible efecto en cadena: la evasión de la piratería y la pugna con la televisión y videojuegos por parte del 3D puede verse afectado, irónicamente, mediante el éxito de esta tecnología, en su expansión a la televisión y videojuegos, redundando por

ARBOR Vol. 187748 marzo-abril [2011] 429-438 ISSN: 0210-1963 
lo tanto en una nueva disminución de espectadores en las sales de cine.

Es necesario aclarar, en cualquier caso, que las gafas estereoscópicas siguen estando presentes y con ellas la incomodidad que acarrean (de posible larga duración en el caso de la televisión y los videojuegos). También hay que tener en cuenta que salvo los productos especialmente realizados para ser consumidos en $3 \mathrm{D}$, el resto de la programación, como espectáculos deportivos, únicamente incluyen una diferenciación de planos muy primitiva, una experiencia muy interesante en un primer momento pero insustancial para un mejor disfrute de un espectáculo deportivo a largo plazo.

Los videojuegos son otro posible destino de la aplicación de tecnología 3D a nuestro entorno doméstico. Al fin y al cabo los videojuegos ya cuentan, debido a su naturaleza, con la interacción e inmersión necesaria para sumergir al jugador en la trama propuesta. Es éste, el jugador, el coresponsable de las imágenes que se perciben y en muchos casos, el protagonista de la historia. El 3D aplicado a los videojuegos es un paso más en el proyecto por conseguir que los jugadores vivan los entornos virtuales en primera persona, como una experiencia personal y para acercar la industria de los videojuegos al sueño de realidad virtual plena y efectiva. Se trataría de una tecnología que nos permita "atravesar el espejo para entrar en la representación e interactuar con objetos tridimensionales, con escenarios y seres que habitan en el mundo virtual" (Machado, 2009, 155). Una vez logrado esto, la imposibilidad de distinguir entre realidad e irrealidad, el siguiente paso sería sustituir la realidad por los signos de lo real (Baudrillard, 2001, 166). Así, nos enfrentamos con la verdadera ironía que esconde este desarrollo constante de la imagen, en la que el 3D es únicamente una parada más: la reproducción de la realidad con la mayor fidelidad y espectacularidad posible.

\section{Conclusiones}

Sin duda llevará un tiempo antes de que los directores y actores de renombre se animen a utilizar la tecnología 3D de forma generalizada para realizar películas, olvidando la larga historia de fracasos de dicha tecnología. También habrá que esperar para que los teóricos y analistas del cine, que se enfrentan a un nuevo fenómeno con herramientas antiguas, dominen la instintiva reacción de rechazo a las nuevas propuestas, tal y como ocurrió con la aparición del sonido ó del cine en color. Sin embargo, lo que se antoja más incierto aún es la respuesta que tendrán los espectadores, a medio o largo plazo, ante una propuesta visual que si bien se presenta ante nuestros ojos con toda su espectacular novedad esconde unas obvias limitaciones en cuanto a lo que nos puede llegar a ofrecer.

El fenómeno en el que se encuentra inmersa la imagen y cultura del siglo XXI va más allá del 3D. En un viraje significativo y reciente sobre los supuestos de realidad en el cine, la digitalizacin provoca que la relación entre la imagen y su referente se vean trasformados, esto implica un paso más (o menos, depende de cómo se mire) a lo establecido por Roland Barthes al decir que la imagen es básicamente una reconstrucción de la realidad y no pretende alcanzar una representación de esta (Barthes, 1964, 1-11). Hoy la imagen no supone una reproducción sino que se acerca más a un simulacro: "Los intercambios mediatizados por el lenguaje electrónico han sustituido la representación simbólica característica del cine narrativo clásico por la simulación numérica que sustituye la ficción por el engaño" (Paz Gago, 2004, 123). Así, el espectador ha perdido la capacidad de discernir si la imagen es real 0 artificial. La cuestión es conocer si existe una correlación entre la fidelidad de la reproducción tecnológica y la sensación de realidad que se obtiene de una película, es decir, entre la imagen artificialmente generada y el efecto de realidad que trasmite la película.

Pese a encontrarnos en una nueva etapa de la cultura visual quizá no es adecuado comparar películas clásicas cómo Casablanca con productos más recientes y tecnológicamente abrumadores como Avatar, pues ambas pretenden transmitir sensaciones diferentes y las imágenes que desprenden también son vistas de modo distinto por el espectador: deleite con la narrativa, convenciones cinematográficas e inmersión en la historia en la primera y fascinación, asombro, escepticismo e inmersión visual en la segunda. No pretendo confrontar aquí ambas maneras de hacer cine, pues no sólo pertenecen a momentos históricos, culturales y tecnológicos diferentes, sino que también el cine, por su pluralidad de generos y estilos, da cabida a diferentes formas de expresión visuales y narrativas. De lo que se trata es de ver al cine como un medio creado y 
evolucionado a partir del mestizaje y por lo tanto analizar y aceptar las posibilidades que las tecnologías de inmersión y (futura) interacción le ofrecen.

El medio cinematográfico debe evolucionar técnicamente, cómo siempre ha hecho, teniendo en cuenta las posibilidades tecnológicas y las demandas de los espectadores. Hoy, la espectacularidad de las imágenes parece estar reñida con una narrativa que de sentido a la película pero producciones cómo Up e incluso Avatar desmienten esta segregación y han de hacer recapacitar a todos aquellos críticos y analistas que niegan la posibilidad de realizar un cine que cuente simultaneamente con contenido y tecnología visual espectacular. El futuro del cine se encuentra irremediablemente unido a la inmersión e interacción con la pantalla y esto no tiene porqué significar la muerte 0 el fin del medio, sino su evolución.

El espectador cinematográfico se adaptará a los cambios como se adaptó al sonido y al color. Es posible que las nuevas generaciones que ahora comienzan a ver cine desestimen consumir películas en las clásicas dos dimensiones, también es probable que éstas terminen siendo adaptadas de forma generalizada a las tres dimensiones, que el 3D tal y cómo lo conocemos hoy fracase ó que evolucione a nuevas formas de reproducir la imagen, pero de lo que no me cabe duda es que el papel del espectador, su debatida actividad/pasividad se verá afectada en un futuro. La distancia simbólica con las imágenes se verá definitivamente alterada con la introducción de la realidad virtual, pero el 3D modificará con anterioridad la distancia visual entre el espectador y la pantalla. El espectador aprenderá a estar alerta a los efectos del 3D y esta inevitable pérdida del efecto sorpresa, de la espectacularidad tecnológica, únicamente se verá reemplazada si el 3D consigue evolucionar. De lo contrario es posible que pase a mejor vida y sea recordado como una moda más que terminó fracasando, convirtiéndose en otro eslabón perdido en la evolución visual, tal y cómo fueron sus múltiples antecesores de los años cincuenta y ochenta.

En cualquier caso, el futuro más cercano del cine 3D se encuentra en el desprendimiento de la interfaz y el abandono de ese último obstáculo que hace presente (y patente) la tecnología, interponiendose entre la imagen y los espectadores. El 3D sin gafas, algo que se ha intentado en diferentes momentos de manera experimental, parece ser el siguiente paso que nos acerque al inevitable matrimonio entre el cine y la realidad virtual, en el cual los videojuegos se verían succionados por la propia inercia de esta tecnología. Esto es, la convergencia total de medios. Estaríamos hablando entonces de un cine en el que la misma espectacularidad de la experiencia ocultará las herramientas de manera absoluta, el truco que genera la magia, que tanto atrae a los espectadores a las salas hoy en día, para aportar una inhibición de la realidad personal y un sumergimiento en la historia que confunda al espectador sobre lo que es real y es ficción.

\section{NOTAS}

1 Cierto es que Hitchcock experimentó con el 3D en Crimen Perfecto (Hitchcock, 1954), pero la película no llegó a ser estrenada en este formato hasta los años 80.

2 Y la aparición del efecto perverso, habría que añadir, de no saber donde

Recibido: 28 de junio de 2009

Aceptado: 31 de octubre de 2009 termina el juego y empieza la realidad o viceversa.

\section{BIBLIOGRAFÍA}

Aaron, Michele (2007): Spectatorship: The Power of Looking, Londres, Wallflower.

Barthes, Roland (1964): Retórica de la Imagen, Buenos Aires, Tiempo Contemporáneo.

Baudrillard, Jean (2001): Selected Writings, Standford, Standford University Press. 
Butler, Christian Charles (2009): "For the Love of Film", Film: Falmouth. http:// krisbutler.co.uk/downloads/For\%20 the\%20Love\%20of\%20Film.pdf.

Casetti, Francesco (1989): El Film y su Espectador, Madrid, Cátedra.

Darley, Andrew (2002): Cultura Visual Digital, Barcelona, Paidós.

Debord, Guy (2000): La Sociedad del Espectáculo, Madrid, Pre-textos.

Díaz Gandasegui, Vicente (2008): (Un) real (un)realities: Exploring the confusion of reality and unreality through cinema. Ph.D. thesis., Cardiff, University of Glamorgan.

La Ferla, Jorge (2009): Cine (y) digital, Buenos Aires, Manantial Texturas.

Fernández Sánchez, Manuel Carlos (2000): "Imágenes en tres dimensiones", Revista Latina de Comunicación Social, 31. http://www.ull.es/publicaciones/ latina/aa2000kjl/z31jl/87sanchez.htm.

García Canclini, Nestor (2007): Lectores, Espectadores e Internautas, Barcelona, Gedisa.

Gunning, Tom (2004): "An Aesthetic of Astonishment: Early Film and the (In) credulous Spectator", en Braudy, Leo, Film Theory and Criticism: Introductory Readings, New York, Oxford University Press, 862-877.

Hayes, R. M. (1989): 3D Movies: A History and Filmography of Stereoscopic Cinema, North Carolina: McFarland.

Katzenberg, Jeffrey (2009): "Monstruos Contra Alienigenas", Fotogramas y Video, Mayo, 112-114.

De Kerckhove, Derrick (2010): "Avatar = Pinocho 2.0 ó El fin de la So- ciedad del Espectáculo", Digithum, 12. http://redalyc.uaemex.mx/redalyc/ pdf/550/55013136003.pdf.

Machado, Arlindo (2009): El Sujeto en la Pantalla, Barcelona, Gedisa.

Manovic, Lev (2001): The Language of New Media, London, MIT Press.

Marsh, Tim y Wright, Peter (2000): "Maintaining the Illusion of Interacting Within a 3D Virtual Space", Presence 2000: 3rd International Workshop on Presence. http://citeseerx.ist.psu.edu/ viewdoc/download?doi=10.1.1.28.707 $2 \&$ rep $=$ rep $1 \&$ type $=$ pdf.

McLuhan, Marshall (1964): Understanding Media: the Extensions of Man, London, Routledge \& Keagan Paul.

Münsterberg, Hugo (2004): The Film: A Psychological Study, New York, Dover.

Obando Arroyave, Carlos (2005): "El video: la emición del signo o (per)versiones de la imagen", Artes, La Revista, n. ${ }^{\circ}$, Vol. 5, 46-60.

Paz Gago, José María (2004): "El Cine ha Muerto. ¡Viva la Realidad Virtual!", Arte y nuevas tecnologías: $X$ Congreso de la Asociación Española de Semiótica, 110-125. http://dialnet.unirioja.es/ servlet/articulo?codigo $=940125$.

Peirón, Francesc (2010): "La perspectiva de que se generalice el cine en $3 \mathrm{D}$ abre una pugna entre los fabricantes de lentes por el mercado", La Vanguardia, 10 de enero.

Pereira Domínguez, Carmen; Solé Blanch, Jordi y Valero Iglesias, Luis Fernando (2010): "Avatar un nuevo paso en el séptimo arte. Algunas consideraciones pedagógico-sociales", Mi ratón. http://www.utp.edu.co/educacion/ raton/antes/miraton 10/textos/avatar. pdf.

Cowan, Matt (2007): "3D in the Modern Era", SMPTE Australia. http://www. reald.com/Content/Media-Presentations.aspx.

Valero Ruiz, Carlos y González Gil, José Alfredo (2000): "Bastidor para filmación 3D estereoscópica", Egráfica. unizar.es. http://www.egrafica.unizar. es/ingegraf/pdf/Comunicacion 17052. pdf.

Vera, Pascual (2008): Único Testigo: El espectador ante el fenómeno cinematográfico, Murcia, edit.um.

Zone, Ray (2007): Stereoscopic Cinema and the Origins of 3D film: 18381952, Kentucky, The University Press of Kentucky.

\section{FILMOGRAFÍA}

Avatar (Dir. James Cameron, 2009).

Beowulf (Dir. Robert Zemeckis, 2007).

Casablanca (Dir. Michael Curtiz, 1942).

Chicken Little (Dir. Mark Dindal, 2005).

Ciudadano Kane (Citizen Kane, Dir. Orson Wales, 1941).

Crimen Perfecto (Dial M for Murder, Dir. Alfred Hitchcock, 1954).

Tiburón 3D (Jaws 3D, Dir. Joe Alves, 1983).

Up 3D (Dir. Pete Docter, P. y Bob Peterson, 2009).

Viaje al centro de la Tierra (Journey to the Centre of the Earth, Dir. Eric Brevig, 2008). 